\title{
Analysis of Factors Responsible For Deforestation in Anambra State of Nigeria.
}

\author{
${ }^{1}$ Anyanwu, J.C., ${ }^{2}$ Nwobu, E. A., and ${ }^{3}$ Osuiwu, B. O. \\ ${ }^{1,2}$ Department of Environmental Sciences, Tansian University, Umunya, Nigeria. \\ ${ }^{3}$ Department of Geography and Meteorology, Nnamdi Azikiwe University, Awka, Nigeria.
}

\begin{abstract}
The research was carried out in four agro-ecological zones of Anambra State. The aim of the survey was to identify major causes of deforestation in the state. Data was generated through questionnaire survey. 30 households were sampled from 20 communities randomly selected from the four agro-ecological zones, making a total of 600 households. Out of the 600 questionnaires sent out to the 20 communities, a total of 489 were recovered. The study established the immediate and remote causes of deforestation in the study area as farming, construction works, rural poverty, population growth, government sponsored projects, fuelwood collection and hunting activities. The study recommended that modern farming techniques that emphasize conservation tillage, as well as plantation forestry, should be embraced as response to deforestation. The study also recommended the reduction of poverty, especially, in the rural areas of the state, as well as the formulation and implementation of policies geared towards the preservation of the forest ecosystem by the state and local governments.
\end{abstract}

Keywords: Biodiversity, Deforestation, Forest land-use, Forest livelihood, Soil degradation.

\section{Introduction}

Deforestation is the conversion of forested areas to non-forest land use such as arable land, pasture, urban use, logged area, or wasteland. Deforestation leads to increased human encroachment upon wild areas, increased resource extraction, threats to biodiversity, soil degradation and extinction of species. According to the Food and Agricultural Organization (FAO, 1982a), the tropics are losing more than 10 million hectares of forest cover annually. In tropical Africa, deforestation exceeds the projected rate of tree planting by a ratio of 29:1 (Kang, Reynolds, and Atta-Krah, 1990). The FAO (1982b) also reported that forest fallow resulting from shifting cultivation practiced in recent times occupies an area equivalent to $28.5 \%$ of the remaining closed forest in Africa, $16 \%$ in America and $22.7 \%$ in Asia. The report also stated that tree cutting for fuel and animal feed production have also contributed to deforestation (FAO, 1982b).

Deforestation occurs because of many reasons. Trees are used as or sold for fuel. Amous (1999) stated that the share of wood fuels in African primary energy consumption represents on average $86 \%$ of total African energy consumption. One reason for forest depletion in West Africa is to plant cash crops such as cotton, cocoa, rubber, kolanuts, gum and oil palm for export. Large-scale deforestation occurs in Anambra State as a result of ignorance of intrinsic value, inadequate environmental laws, lack of ascribed value and poor forest management practices. The reliance on area expansion to meet the needs of rapidly increasing human populations has also resulted in increased deforestation in Anambra State. Deforestation is a serious cause of environmental problems in the state. These problems include erosion, loss of soil fertility, loss of forest products like medicinal plants and fruits, extinction of species, changes in climatic conditions, and displacement of indigenous people. Poverty is an important factor of deforestation in most African countries. The New York Times (2009) reports that among countries with a per capita GDP of at least US $\$ 4,600$, net deforestation rates have ceased to increase.

\section{Materials And Methods}

Study Area: This study was carried out in Anambra State of Southeastern Nigeria with the study sites located in four agro-ecological zones of the state established from the soil and vegetation maps modified from Ofomata (1975). Anambra state lies between longitudes $6^{0} 35^{1} \mathrm{E}$ and $7^{0} 21^{1} \mathrm{E}$, and latitudes $5^{0} 40^{1} \mathrm{~N}$ and $6^{0} 45^{1} \mathrm{~N}$.

The climate is tropical with high annual rainfall ranging from $1,400 \mathrm{~mm}$ in the north to $2,500 \mathrm{~mm}$ in the south, with a mean monthly temperature of $27.6^{\circ} \mathrm{C}$. The natural vegetation in the greater part of the state is tropical dry or deciduous forest, which, in its original form, comprised tall trees with thick undergrowth and numerous climbers. 


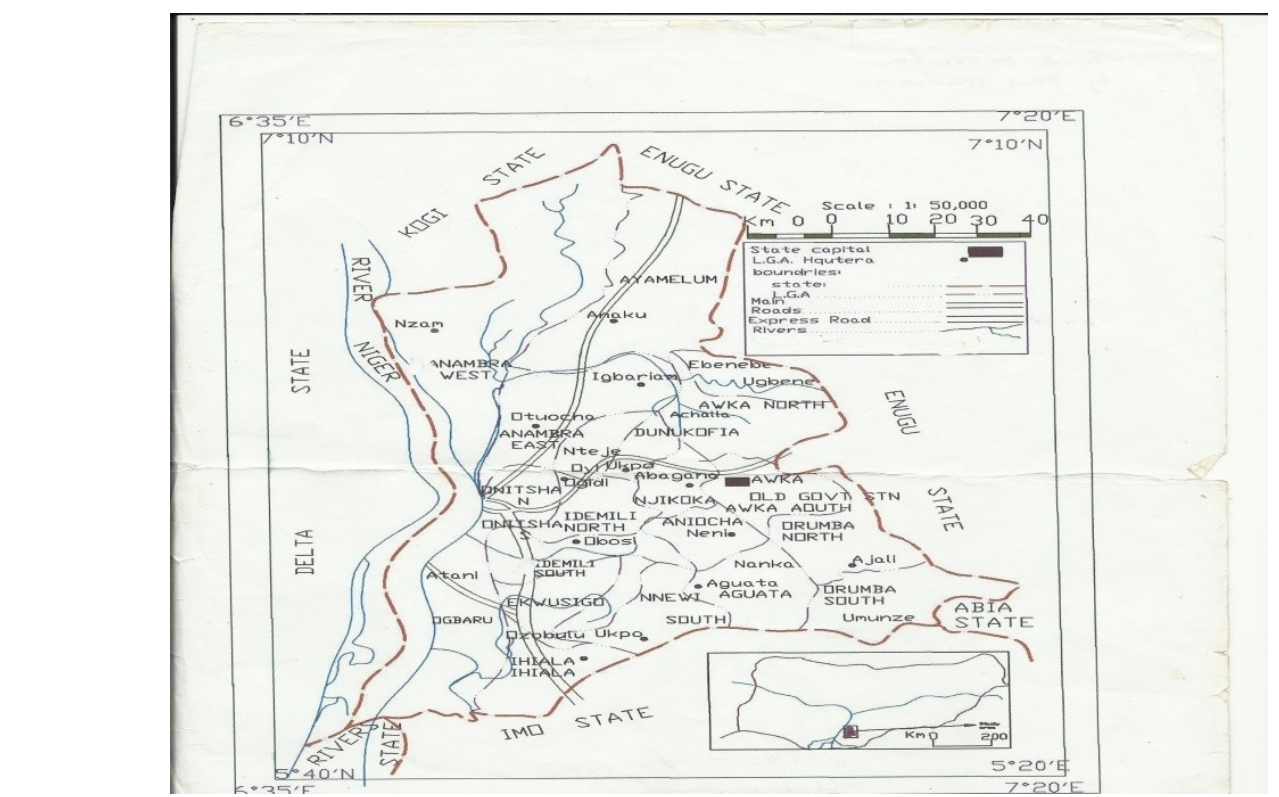

Source: Ministry of Land and Survey, Awka.

Figure 1. Anambra State, Nigeria.

2.1. Data Collection and Analysis: Data was generated through questionnaire survey. The questionnaire covered various socio-economic and demographic characteristics of the households, forest livelihood and forest land-use. Socio-economic factors include age and education of the household head, family size, land holdings, and income composition. Other factors include the distance to the nearest cultural or catchment forest, access to credit facilities as well as problems encountered with deforestation. The structure of the questionnaire was designed to meet the objectives of the study and pre-coded for ease of data collection and analysis. The questionnaire was open-ended in some questions, allowing for flexibility in responding to the questions. Some other questions were close-ended restricting the respondents to tick the options of interest to them. The questionnaire was administered to all the household heads in selected villages. The criteria for village selection were based on agricultural practices and accessibility to forest.

Thirty households were sampled from each of the twenty communities, making a total of 600 households. In administering the questionnaire, the family was the basic unit of survey. The heads of households were mainly the respondents. were recovered.

Out of the 600 questionnaires sent out to the 20 communities, a total of 489

\section{Results And Discussion}

Distribution of Respondents according to Socio-economic Characteristics: Table 1 and Figures 1, 2 and 3, show the result of the distribution of respondents according to socio-economic characteristics. Respondents were mostly males (85\%) in their middle and old ages (4land above) (74\%) with most of them having attended Primary school (45\%) and possessed at least a hectare of farmland (72\%). The dominance of the aged population in this survey is an indication that agriculture has been abandoned by the youth with its attendant food insecurity as the old people are mostly limited to subsistence farming most of them adopting outdated and environmentally unfriendly agricultural techniques including bush burning and improper tillage of the soil. This invariably contributes to deforestation and soil degradation. Again, the fact that most of them attained primary school (45\%) is an indication that they may not be in tune with new farming techniques that lay more emphasis on conservation tillage, contour plowing to control erosion, and adoption of intensive farming rather than extensive farming to control deforestation and prevent loss of valuable species of economic and medicinal values. Their academic attainment may also make it difficult for them to see the correlation between clearing forests and contemporary issues of climate change and global warming. 
Table 1: Distribution of respondents according to socio-economic characteristics

\begin{tabular}{|c|c|c|}
\hline Socioeconomic characteristics & Number of respondents $\mathrm{F}$ & Percentage \\
\hline \multicolumn{3}{|l|}{ Gender } \\
\hline Male & 416 & 85 \\
\hline Female & 73 & 15 \\
\hline \multicolumn{3}{|l|}{ Ages (years) } \\
\hline 21-30 & 39 & 8 \\
\hline $31-40$ & 88 & 18 \\
\hline $41-50$ & 245 & 50 \\
\hline 51-and above & 117 & 24 \\
\hline \multicolumn{3}{|l|}{ Education } \\
\hline No formal education & 29 & 6 \\
\hline Primary education & 220 & 45 \\
\hline Secondary education & 171 & 35 \\
\hline Post- secondary education & 69 & 14 \\
\hline \multicolumn{3}{|l|}{ Farm size (ha) } \\
\hline Below 1.1 & 245 & 50 \\
\hline $1.1-2.0$ & 108 & 22 \\
\hline $2.1-3.0$ & 88 & 18 \\
\hline Above 3.0 & 49 & 10 \\
\hline
\end{tabular}

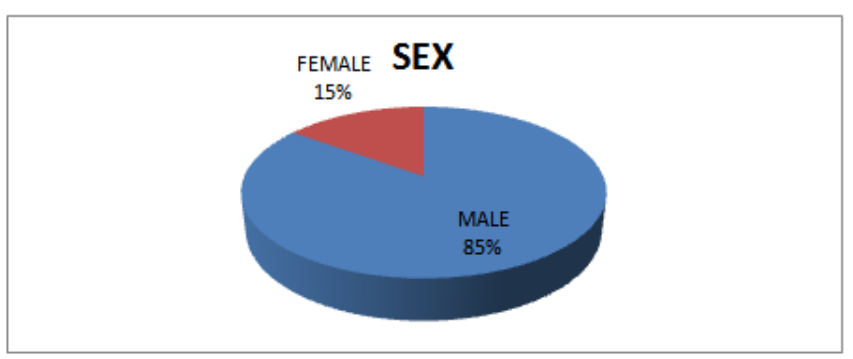

Fig.1. Percentage Distribution of Respondents According to Sex

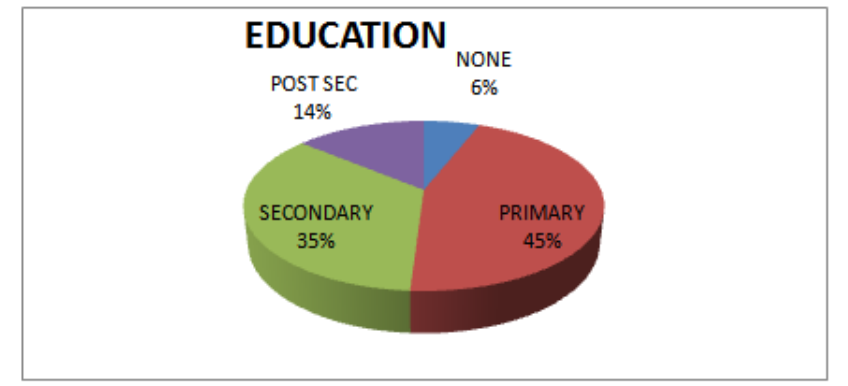

Figure 2. Percentage Distribution of Respondents According to Education

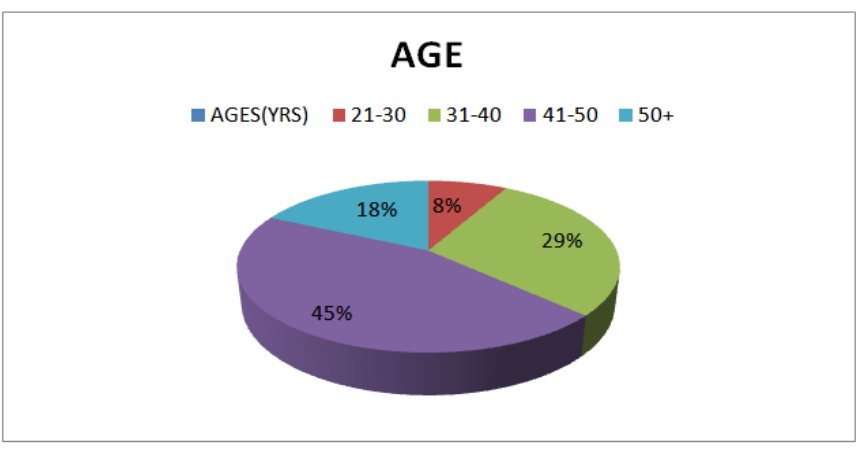

Figure 3. Percentage Distribution of Respondents According to Age 
The implication of this finding is that there is need to create more awareness on the causes and impact of deforestation in the state, especially amongst the rural farmers since they are responsible for most of the subsistence farming activities in the state. The youths, particularly graduates, should be encouraged to get into agriculture since they will be more innovative and knowledgeable on modern farming techniques, which place more emphasis on environmental protection and conservation practices and at the same time being able to use less land to produce more food for the teeming population. The fact that most of the respondents cultivated only 1 hectare of farmland is an indication of a problem of loss of soil fertility as a result of continuous cropping.

This would have serious effect on the productivity of the soil in terms of crop yield and will portend great danger in the area of food security due to the rapid increase in population in the state, if efforts are not geared towards soil fertility restoration.

\section{Analysis of the Responses to Factors Responsible for Deforestation:}

The result of analysis of the responses to factors responsible for deforestation in the study area is presented in a chart (Figure 4) which revealed that most of the respondents attributed farming activities (219 or $45 \%$ ) as the major factor responsible for deforestation in the study area followed by construction works (61 or $12 \%$ ), population growth (56 or $11 \%$ ) and rural poverty (46 or 9\%). In Zone A, also shown in Figure 5, farming activities ( 63 or $54 \%$ ) was attributed to be the major cause of deforestation followed by rural poverty (12 or $10 \%$ ) and collection of wood for sale ( 9 or $8 \%$ ). In Zone B (Figure 6) most of the respondents attributed farming activities $(41$ or $30 \%)$ as the major factor responsible for deforestation, followed by construction works (29 or $21 \%$ ) and population growth (25 or 18\%). Also in Zone C (Figure 7), farming activities (44 or 39\%) was attributed to be the major cause of deforestation in the zone, followed by population growth (19 or 17\%) and construction works (16 or 14\%). The analysis further revealed that most of the respondents in Zone D (Figure 8) attributed farming activities ( 71 or $53 \%$ ) as the major cause of deforestation, followed by rural poverty (17 or $12 \%$ ), and hunting activities (12 or $9 \%$ ). The implication therefore is that farming activities is regarded as the overwhelming cause of deforestation in each agro-ecological zone as well as the entire study area. The analysis (Figure 4) also revealed that the respondents regarded fuel-wood collection (27 or 6\%), collection of wood for sale (30 or $6 \%$ ), government sponsored projects ( 28 or $6 \%$ ) and hunting activities ( 23 or $5 \%$ ) as the least factors responsible for deforestation in the study area. Figure 9 further presents a comparative analysis of responses to the factors of deforestation in the different agro-ecological zones of the state.

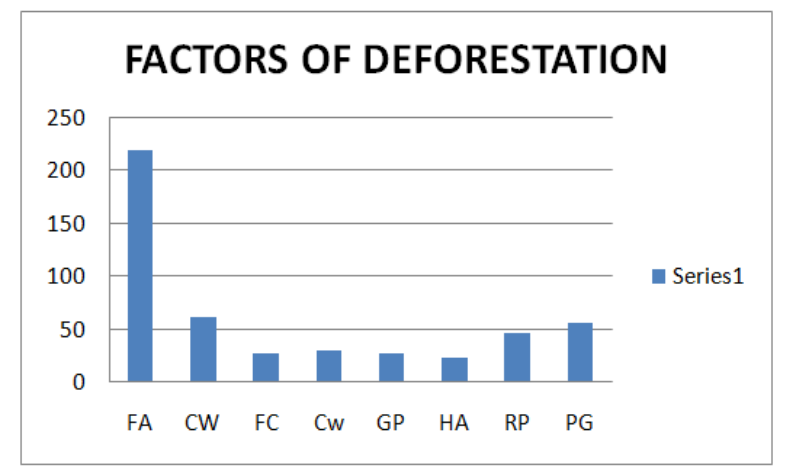

Figure 4. Responses to Factors Responsible for Deforestation in the Study Area.

KEY: FA $=$ Farming Activities, $\mathrm{CW}=$ Construction Works, $\mathrm{FC}=$ Fuel Wood Collection, $\mathrm{Cw}=$ Collection of Wood for Sale, GP $=$ Government Sponsored Projects, HA $=$ Hunting Activities, $\mathrm{RP}=$ Rural Poverty, $\mathrm{PG}=$ Population Growth .

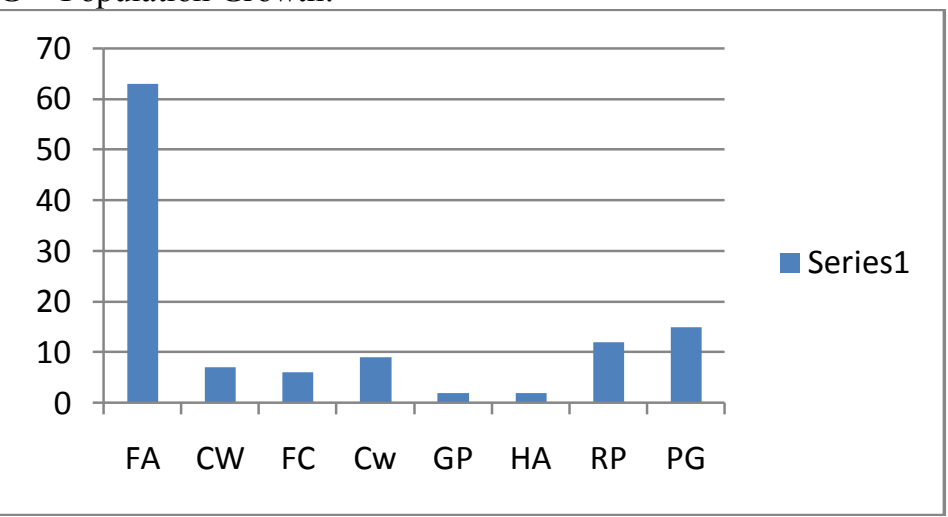

Figure 5. Responses to Factors for Deforestation in Zone A 


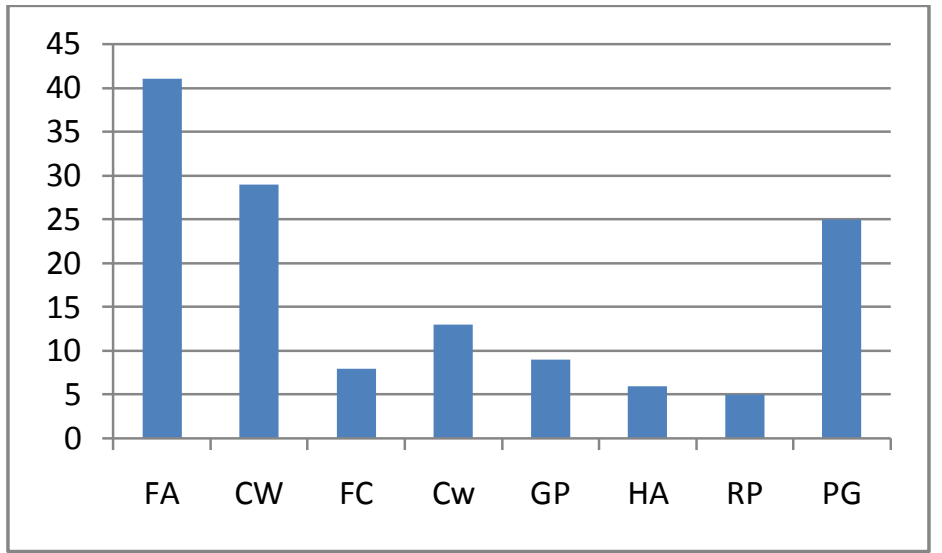

Figure 6. Responses to Factors for Deforestation in Zone B

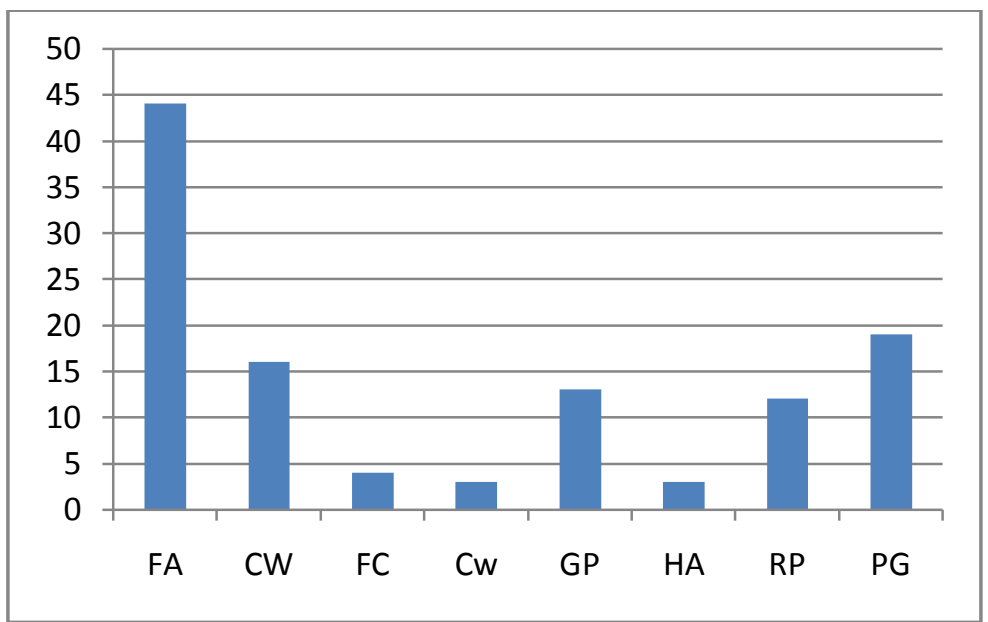

Figure 7. Responses to Factors for Deforestation in Zone C

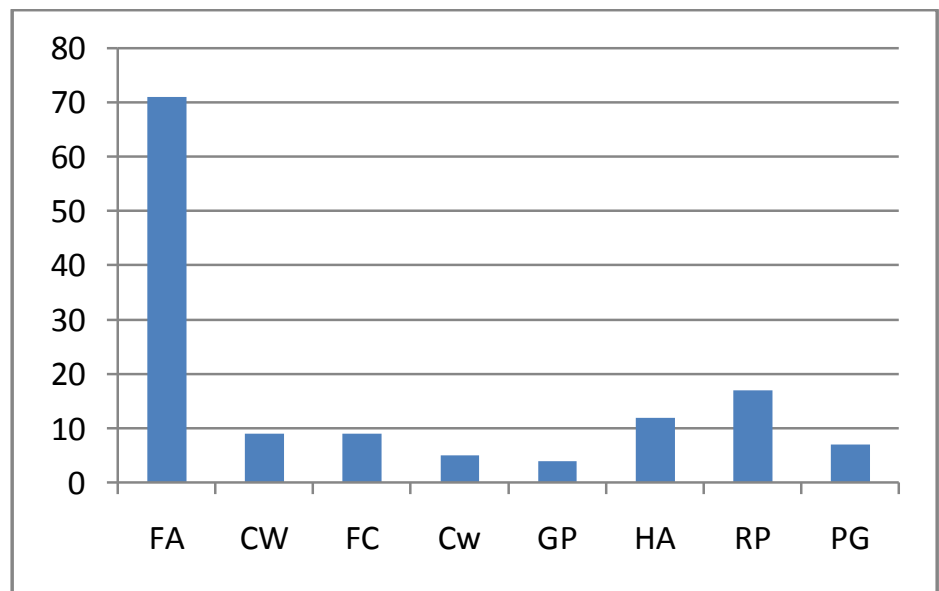

Figure 8. Responses to Factors for Deforestation in Zone D 


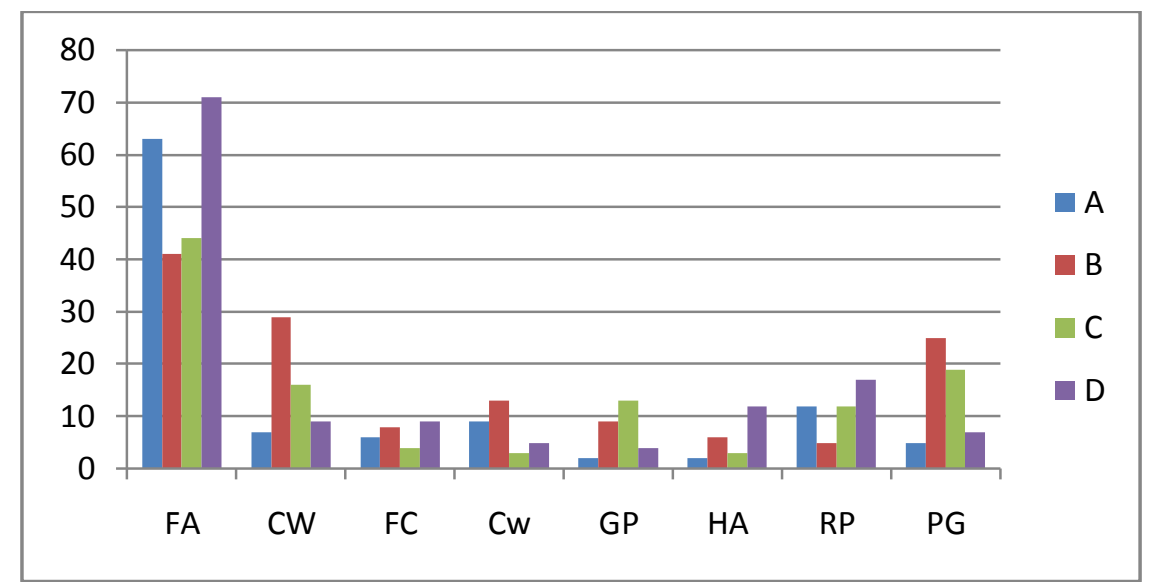

Figure 9. Factors Responsible for Deforestation in Different Agro-ecological Zones

As a result of increase in population in the state, people resort to clearing of forest to provide shelter and to plant crops either for subsistence or for sale in the markets in order to eke out a living. The high level of unemployment and poverty in the rural areas has forced people to exploit forest resources in an unsustainable way and to clear the forests for agricultural purposes. This areal expansion of agricultural land has impacted negatively on the biodiversity and soil condition in the state. A lot of those with one form of employment or the other also take to farming as a way of supplementing the meager resources from their regular jobs. In the course of this study, it was noticed that farming activities were greater in those areas of the state with high poverty index such as Anambra West, Anambra East, Awka North, etc. These areas are also regarded as the food baskets of the state for the above reason and partly because of the fertile soil in the area occasioned by alluvial deposits caused by seasonal flooding in the area. Lack of adequate storage facilities and poor road network to transport some of these farm produce has led to much of the produce perishing either in storage or en route to the market. As such, the farmers continue to incur losses and remain impoverished.

There is a poverty-deforestation-cycle in some of the study communities. Clearance of forest for the purpose of agriculture has exposed the soil to erosion and leaching of nutrients. This has led to low farm productivity as complained of by most of the farmers. Low farm productivity in turn results in low farm income or poverty. Thus poverty has emerged as a serious problem in these communities. Since the government is desirous of food sufficiency and environmental protection in the state, there is urgent need to address the issue of poverty, especially in the rural areas. The rapid construction works going on in the state is an attestation to the rate of modernization and urbanization in the state. Rural-urban migration has led to the overstretching of the facilities in the urban areas resulting in the need for expansion of infrastructural facilities by both the government and private individuals. This could be seen in the form of road construction, building of houses, establishment of industries, markets, schools, hospitals, and a host of others, all of which require the destruction of forest ecosystem. In as much as infrastructural facilities are essential for the development of the state, there is need to strike a balance between construction works and preservation of forest ecosystem. The government should ensure that every project or construction work, no matter how minuscule, large or vital to economic growth must be subjected to Environmental Impact Assessment (EIA). For now, it appears only those multimillion naira projects are the ones that are subjected to EIA in the state. If EIA is carried out on every project, small or big, it will help to ascertain the impact of such projects on the environment. If the project impacts negatively on the environment particularly forest and soil condition, then the impact should be mitigated, otherwise the project should be abandoned.

Hunting activities were also prevalent in many communities particularly, Oba, Igbariam, Ebenebe, Otuocha and others. It was a common sight to see young people and their dogs traversing one forest or the other with sticks, matchets and catapults in search of rodents, squirrels, alligators, and bush fowls. In most cases, they set a portion of the forest/bush ablaze in a bid to force the animals out from their hideouts. But this in addition to destroying animal habitats has led to the destruction of medicinal plants and other valuable plant species. The implication of this observation is that there is need for legislation against bush or forest burning so as to protect these important plant and animal species of economic and medicinal values. Further more, employment opportunity should be provided for these hunters most of whom are youths in order to keep them out of the forests. It was also observed that some of the hunters were students who wanted to raise money to augment what they would get from their parents to be able to pay their school fees.

This study also noted an upsurge of fuel wood collection in most of the communities studied. The reason could be attributed to the high cost of kerosene which is beyond the reach of the rural poor. 


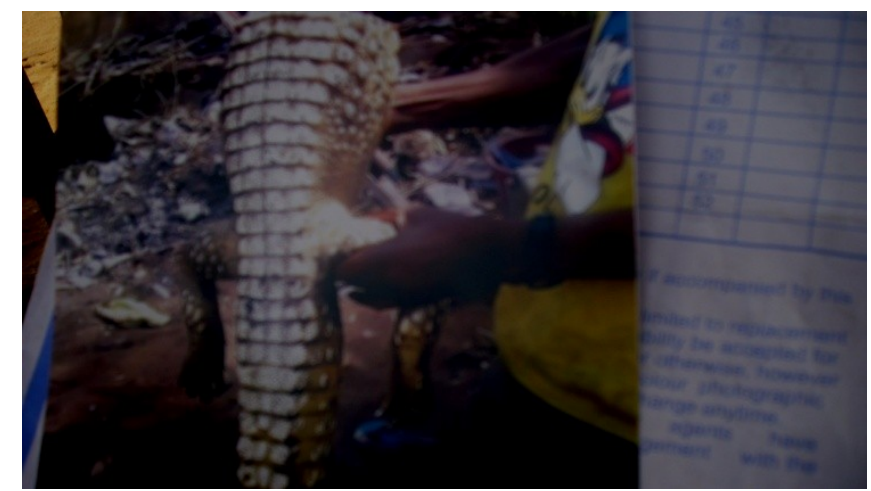

Plate 1: A Hunter slaughtering Alligator caught in Oba Forest

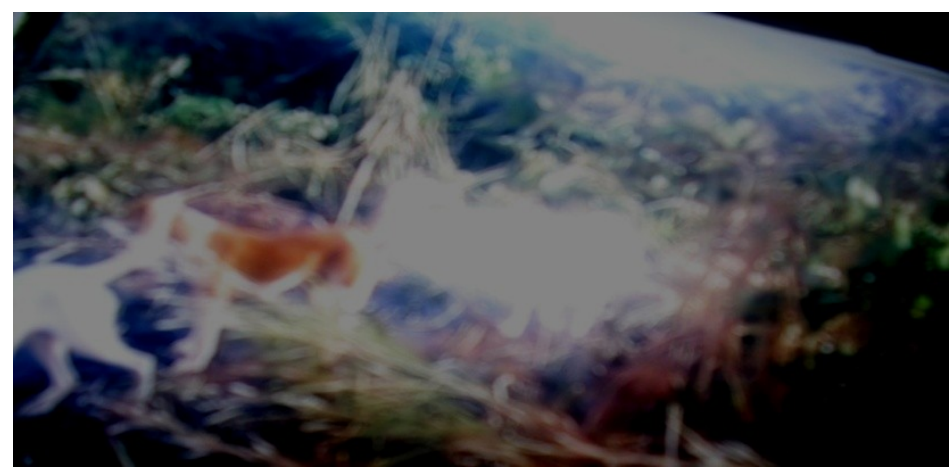

Plate 2: Hunting Dogs in Igbariam

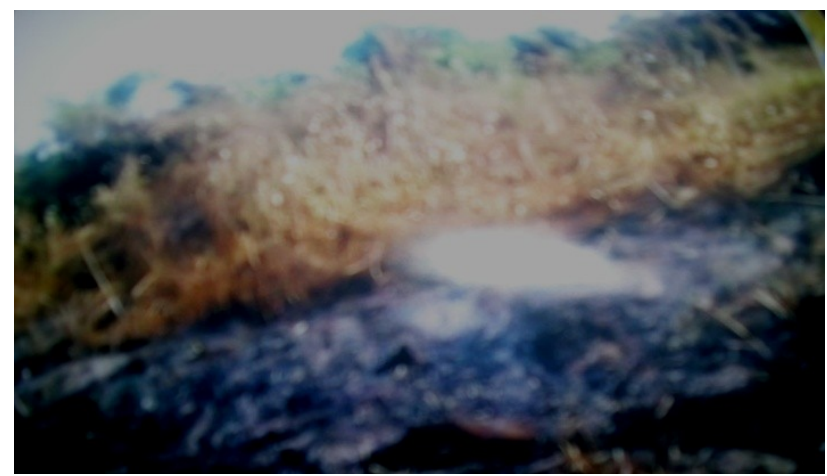

Plate 3: Bush Burning in Ihiala

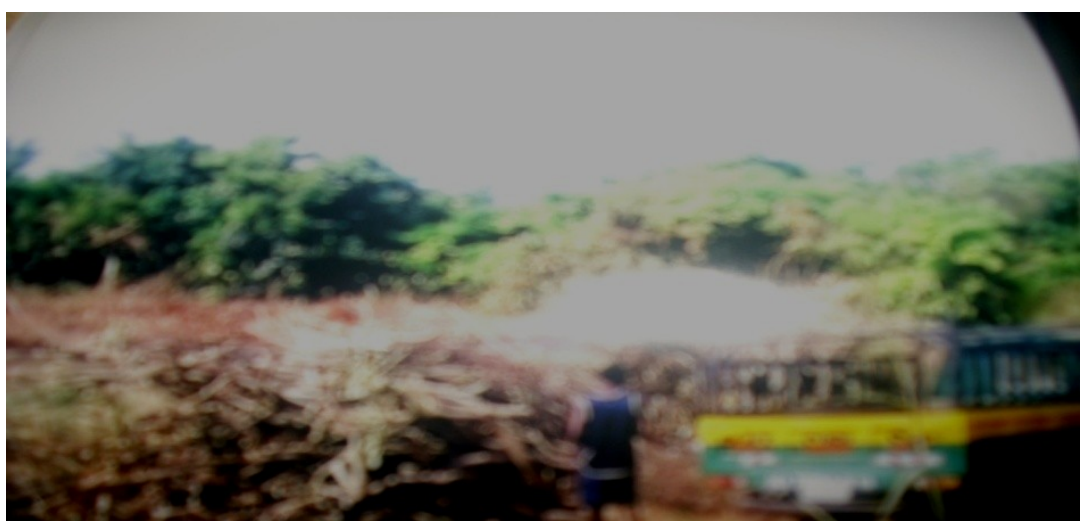

Plate 4: Fuelwood Collection in Oba

\subsection{Principal Component of Factors Responsible for Deforestation in the Study Area}

We further used principal component analysis to explain the factors of deforestation in the study area. The major components in the matrix are identified on the basis of Kaiser (1959). However, the significance of 
the variables that are related to each component was determined by those variables with loading, above 0.60 .

Three principal components (Table 2) were extracted explaining $77.06 \%$ of observed variation in the data set. We retained Eigen values equal to or greater than 1 according to Kaiser (1960). Component I has high positive loading on construction works $(0.8103)$ and population growth $(0.8387)$, and high negative loading on farming activities (-0.899) and rural poverty $(-0.7418)$. Component I has an eigen value of 3.53 and explains $44.11 \%$ of the observed variation in the data set. Component I reflects the pressure on forests as a result of population growth, farming activities, rural poverty and large scale construction works. This component is also indicative of the fact that population growth, poverty and agricultural activities, both subsistence and commercial, are the primary and proximate causes of deforestation in the study areas. Component II has only one variable loading on it. It has high positive loading on government sponsored projects $(0.8512)$ and has an eigen value of 1.48 . It explains additional $18.45 \%$ of variation in the data set and together with Component I explain a total of $62.56 \%$ of the variation in the data input. Component II explains the contribution of government sponsored projects in the degradation of forest ecosystem. Component III has an eigen value of 1.16 and accounts for a percentage contribution of 14.49 in the total variance. It has high positive loading on fuelwood collection (0.7084) and hunting activities (0.6091). This component explains the impact of collection of wood and hunting activities on deforestation.

From Table 2, we extracted the variables with the highest loadings from each of the three components. These extracted component defining variables are farming activities, construction works, rural poverty, population growth, government sponsored project and fuel wood collection. The underlying components have been identified to be responsible for $77.06 \%$ of the factors responsible for deforestation in the study area. The $22.94 \%$ unexplained variation may be caused by other factors including natural hazards.

Table 2: Varimax Rotated Component Loadings of Factors Responsible For Deforestation in the Study Area

\begin{tabular}{|c|c|c|c|}
\hline \multicolumn{4}{|c|}{ Components } \\
\hline Factors & I & II & III \\
\hline Farmining Activities & $\underline{-0.899}$ & -0.1757 & 0.0385 \\
\hline Construction Works & $\underline{0.8103}$ & 0.2571 & -0.02429 \\
\hline Fuel Wood Collection & -0.1756 & 0.423 & $\underline{0.7084}$ \\
\hline Collection of Wood for sale & $\underline{0.6611}$ & -0.5029 & 0.3818 \\
\hline Government Spon. Pri. & 0.3811 & $\underline{0.8512}$ & -0.2452 \\
\hline & & & \\
\hline Hunting Activities & -0.4442 & 0.3034 & $\underline{0.6091}$ \\
\hline RP = Rural Poverty & $\underline{-0.7418}$ & 0.3395 & -0.2527 \\
\hline Population Growth & $\underline{0.8387}$ & 0.1224 & 0.1226 \\
\hline Eigen Value & 3.52916 & 1.4757 & 1.15972 \\
\hline \% Variance & 44.114 & 18.446 & 14.496 \\
\hline Cum. \% Contribution & 44.114 & 62.56 & 77.06 \\
\hline
\end{tabular}

\section{Conclusion}

From the above analysis and interpretation of the principal components, the defining variables were subdivided into two. These are (1) proximate (i.e. primary and direct) causes of deforestation such as farming, construction works, hunting, fuelwood collection, and (2) underlying or predisposing (i.e. remote and indirect) factors responsible for deforestation such as government sponsored projects, rural poverty and population growth. The proximate causes of deforestation may be as a result of the underlying causes. For instance poverty may lead to hunting and fuelwood collection. Population growth and government sponsored projects may lead to increase in construction works. The implication of the above, however, is that both the proximate and underlying or predisposing factors are all responsible for deforestation and should be properly addressed so as to curb the trend of deforestation in the study area.

The use of varimax rotation has shown a good spread of significant variables between the three components and the PCA has yielded the factors of deforestation outlined in Table 3 above.

Since farming has been implicated as one of the primary causes of deforestation. There is need to adopt farming systems that encourage conservation tillage. This should include introduction of organic farming method, hydroponics, greenhouse gardens, slash and char rather than slash and burn, as well as alley farming in which crops are interspersed with small trees.

Also, since poverty bolsters deforestation and the resulting biodiversity loss, efforts should be made to satisfy the basic survival needs of the people. This can be done through poverty alleviation programmes and 
interventions. Government should create jobs and empower the people in addition to providing critical infrastructural facilities such as electricity which will in turn drive the creation of more jobs.

Both the state and local governments should formulate and implement policies that will enhance conservation of forestry. This should include economic, demographic and land tenure policies.

\section{References}

[1]. Amous, S. (1999). "The role of wood energy in Africa," in Wood Energy Today for Tomorrow (WETT) Regional Studies. FAO Forestry Department Working Paper FOPW/99/3, FAO, Rome.

[2]. FAO (1982a). "Conservation and Development of Tropical Forests Resources," Forestry paper 37 FAO, Rome.

[3]. FAO (1982b). "World soil charter," Bulletin of the International Society of Soil Science. Vol. 62, pp. 30-37.

[4]. Kaiser, H.F. (1959). "Computer programme for varimax rotation in factor analysis," Educational and Psychological Measurement, Vol. 19. pp. 415-418.

[5]. Kaiser, H.F. (1960). "The application of electronic computers to factor analysis," Educational and Psychological Measurement, Vol. 20, pp. 141-151.

[6]. Kang, B.T., Reynolds, L., and Atta-Krah, A.N. (1990). Alley Farming, IITA Reprint, Ibadan.

[7]. Ofomata, G.E.K. (1975). Nigeria in Maps: Eastern States. In G.E.K. Ofomata (Ed). Vegetation Types and Soils. pp. 30-45. Ethiope Publishing House, Benin, Nigeria.

[8]. The New York Times, January 30 (2009). New Jungles Prompt a Debate on Rain Forests. 